\title{
DISCURSO PROFERIDO PELO PROFESSOR NEWTON DE LUCCA
}

\author{
Newton De Lucca \\ Professor Associado do Departamento de Direito \\ Comercial da Faculdade de Dircito da \\ Universidade de São Paulo
}

Queridos Amigos e Amigas,

Escuso-me de declinar o nome de todas as altas autoridades que me honram com a sua presença, dos presidentes das várias entidades que apoiaram a realização deste evento e de tantos quantos, por razões da mais variada espécie, mereceriam que eu, expressamente, os enunciasse... Todos, na verdade, de fato e de direito, mereceriam que eu o fizesse...

E, por tal razão, todos haverão de perdoar o deslize, pois desejo fazer essa intervenção da forma mais breve possível, não-obstante a extrema inabilidade que tenho para sintetizar as coisas. No meu caso, efetivamente, parece ela beirar os "limites da perfeição"...

Peço vênia, pois, para saudar indistintamente a todos os presentes, nas pessoas dos Eminentes Ministros Sidney Sanches, do Supremo Tribunal Federal, e dos Ministros Fontes de Alencar, Ruy Rosado de Aguiar, Jorge Scartezzini e Castro Filho, de nosso Superior Tribunal de Justiça, que tanto engrandecem esta noite, propiciandome a íntima conviç̧ão de que Deus pode ter sido extremamente avaro comigo na distribuição das virtudes humanas, mas foi deveras pródigo nas amizades com as quais tão generosamente ter-me-á aquinhoado...

Tentarei, assim, ser bastante singelo... Sobretudo agora, após as cativantes palavras do Eminente Professor Rangel Dinamarco a quem tenho o privilégio de chamar simplesmente de Cândido, por generoso desígnio de Deus - que, por si sós, não-só repuseram a verdade sobre o significado desta confraternização, mas também resgataram o incontrolável amargor que na alma se instalara, após a infeliz tentativa de conspurcar-se a grandeza do gesto da Comissão Organizadora deste encontro...

Sim, sem dúvida, o mais razoável é tentar conter-me, na medida do possível. Não será fácil, por certo, pois acho que nasci mesmo marcado com esse estigma incontrolável de me emocionar demais com a aventura da vida... 
E exatamente por isso, julgo-me no direito e no dever de dar um sentido maior para que tantas pessoas se achem reunidas nesta festa para homenagear uma ligura menor, sem nenhuma falsa modéstia...

Penso que a noite de hoje só pode ser interpretada como um gesto de amor... Nada deixei de meritório ou de significativo, na verdade, ao longo desses anos de jurisdocência, que pudesse justificar uma homenagem...

Diz o Livro do Eclesiástico 11:

"Não te glorie nunca de tuas vestes, não te engrandeças no dia em que fores homenageado, pois só as obras do Altíssimo são admiráveis, dignas de glória, misteriosas e invisíveis."

É com esse espírito bíblico que aceitei participar desta noite. Nunca fui e não o sou, deveras - quer uma inteligência fulgurante, quer um lutador incansável, quer um jurista destacado em nossa comunidade, malgrado tantas manifestações que me chegam em sentido contrário, só levadas em conta por mim pelo seu caráter evidentemente carinhoso...

Muito menos, quero crer, posso considerar-me um professor reconhecido na própria Faculdade de Direito da Universidade de São Paulo, na qual ora completo trinta anos, apenas percebidos, talvez, pelos velhos amigos dos bancos acadêmicos, a quem, emocionadamente, já pude abraçar e dos quais trago tão doces recordações...

Resta-me o consolo, porém, de que todos esses anos - conquanto insignificantes em si foram vividos com a mais amorosa e intensa dedicação, ainda que, junto com eles, já tenham soçobrado as derradeiras possibilidades de meu sonho...

Alguns prêmios recebidos, no fundo - que pudessem, eventualmente, se afigurar como algo relevante -, também nada significam. Hoje posso ver, com absoluta clareza, que em nada me engrandecem. Eles foram outorgados por homens e estes são de uma falibilidade que, muita vez, ultrapassa os limites do inverossímil...

É por isso tudo que permito-me repetir esta noite não pode ser considerada outra coisa senão um ato de amor...

Esse sublime sentimento - o Amor -, por incrível que possa parecer, é absolutamente estranho à Ciência Jurídica. Nossa Constituição Federal, em nenhum de seus comandos, contempla a expressão amor. O nosso Código Civil de 2002, prestes a entrar em vigor, retirou a palavra que, no Código de 1916, aparecia uma única vez, 
relativamente à gestão de negócios e que se achava empregada de forma absolutamente infeliz, pois "o amor a seus próprios interesses" muito mais se aproxima do egoísmo do que, propriamente do amor, no sentido genuíno e cristão dessa expressão, conforme estou anotando nos comentários ao novo Código Civil, ora em fase de elaboração, outra dívida que tenho pendente, aliás, desta feita com o Eminente Ministro Sálvio de Figueiredo.

Poderia, quem sabe, a palavra amor ser utilizada, em toda a sua resplandescência, em outras paragens do Direito, quando estivesse em causa, por exemplo, a criança, a família ou a dignidade da pessoa humana... Mas essa é uma tarefa que ficará para os nossos netos, pois não fomos capazes de levá-la adiante pcla simples e boa razão de que a nossa sociedade - mergulhada numa espécie de desorientação espiritual sem precedentes na História da Humanidade - deixou-se seduzir irremediavelmente pelo fascínio da razão e da técnića triunfantes, tornando-se axiologicamente cega em relação à condição última do homem...

Estou convencido, por outro lado, de que grande parte das pessoas não deseja o amor banido de seus corações e a realização desta noite é uma prova - esta sim, inequívoca do que vem a ser o amor... Aliás, nada como aquele saber das experiências feito, como diria o grande Camões... Ao apreciar, doravante, os pedidos de tutela antecipada que me chegam a mancheias, passarei a ter presente, não apenas os ensinamentos do querido mestre Cândido Dinamarco, mas um outro conceito do que vem a ser a tal prova inequívoca...

É mais do que claro que, ao dizer que se trata de um ato ou de um gesto de amor, não estou diminuindo, nem mesmo remotamente, a grandeza deste encontro. Pelo contrário, ele assume, antes, dimensões infinitamente maiores do que se movido fosse por qualquer outro sentimento... A circunstância de não haver nada de especial para ser comemorado nesta noite, torna-a encantadoramente especial... Por ser um ato de amor, ela parece indefinível... Ou, se definível for, há que sê-lo pela lírica camoniana:

“...um não sei que, que nasce não sei onde vem não sei como e dói não sei por que..."

Não posso deixar de destacar, entre tantos, alguns gestos - todos eles também cheios de amor que ficarão para sempre gravados nos porões de minha memória barroca...

Como esquecer-me daquela vinda de um aluno ouvinte de minha disciplina na pós-graduação da Universidade de São Paulo - da qual não posso extrair 
nenhum trecho, por questão de recato intelectual -. mas que entrará para o livro autobiográfico, que na paz da montanha, se Deus quiser, ainda hei de escrever... Esquecer...Quem há de...? como diria o Poeta...

Obrigado, Meu caro Emerson, a sua carta comoveu-me, como nos comove o canto de um cisne, fazendo-me lembrar daqueles versos de Camões:

"Não mais, Musa, não mais, que a lira tenho

destemperada e a voz enrouquecida

e não do canto, mas de ver que venho

cantar a gente surda e endurecida.

O favor com que mais se ascende o engenho

Não no dá a Pátria, não, que está metida

no gosto da cobiça e da rudeza

duma austera, apagada e vil tristeza..."

É no mínimo incrível que uma pessoa que me conheça há tão pouco tempo possa já me conhecer tanto assim... Embora jovem ainda, você, Meu Caro Emerson, já está preparado para viver a grande solidão dos intelectuais... Lembre-se sempre daquela famosa passagem de Sartre:

"Começa para o homem a angústia, e o abandono e os suores de sangue, quando não pode mais ter outra testemunha senão ele próprio."

Uma outra querida professora da Bahia - que dizia não ter palavras para exprimir o seu carinho, mas queria encontrá-las a todo custo para o meu reconforto da alma -, sabedora de meu gosto por Fernando Pessoa, não resistiu à tentação de me enviar, como sucedâneo, um trecho da $1^{\text {a }}$ Parte do Livro do Desassossego, do qual extraio a seguinte passagem:

"Tenho assistido, incógnito, ao desfalecimento gradual da minha vida, ao soçobro lento de tudo quanto quis ser. Posso dizer, com aquela verdade que não precisa de flores para se saber que está morta, que não há coisas que eu não tenha querido, ou em que tenha posto, um momento que fosse, o sonho só desse momento, que se me não tenha desfeito debaixo das janelas como pó de pedra caído de um vaso de andar alto. Parece, até, que o Destino tem sempre procurado, primeiro, fazer-me amar ou querer aquilo que ele mesmo tinha disposto para que no dia seguinte eu visse que não tinha ou teria. 
Espectador irônico de mim mesmo, nunca, porém, desanimei de assistir à vida. E, desde que sei, hoje, por antecipação de cada vaga esperança que ela há- de ser desiludida, sofro o gozo especial de gozar já a desilusão com a esperança, como $\mathrm{lm}$ amargo com doce, que torna o doce doce contra o amargo. Sou um estratégico sombrio, que, tendo perdido todas as batalhas, traça já, no papel de seus planos, gozando-lhe o esquema, os pormenores da sua retirada fatal, na véspera de cada sua nova batalla.

Uns dizem que sem esperança a vida é impossivel, outros que com esperança é vazia. Para mim, que hoje não espero nem desespero, ela é um simples quadro externo, que me inclui a mim, e a que assisto como um espetáculo sem enredo, feito só para divertir os olhos - bailado sem nexo, mexer de folhas ao vento, muvens em que a luz do sol muda de cores, arruamentos antigos, ao acaso, em pontos desconformes da cidade."

E, malgrado a inevilável increpação dos exagcros literários e do excesso de cmoção que costumo pôr cm tudo aquilo que laço, seja-me permilido ler um trecho da inolvidável carta a mim dirigida pelo Eminente Presidente do nosso Instituto dos Advogados de São Paulo, Dr. Nelson Kojransky:

"Saiba, outrossim, que para o IASP, constitui motivo de júbilo e de grande orgulho poder contar; dentre os membros desta casa, com a pessoa proeminente de Vossa Excelência, que tanto tem feito em prol da cultura brasileira, não só como jurista, professor; poeta, mas também, como um dos magistrados que mais tem enriquecido o E. Tribunal Regional Federal da $3^{a}$. Região."

Bem, sei que é preciso tentar cumprir a difícil promessa, feita no início, de me conter ao máximo. Seria de uma pieguice intolerável ou de um cabotinismo que não combina com a minha alma simples, impor a todos os que me ouvem a repetição das frases que me acalentaram durante esse prolongado período em que me debati na dúvida entre o seguir e o parar...

Como pode um ser, afinal, evaporado pela "lira insana" e arrastado pclo "tropel das paixões" nos versos imorredouros de Bocage, tentar seguir em frente?...

A bem da verdade, o excesso de emoção fez-me envelhecer mais rápido. E ela deve ter cansado muito aos alunos também. Alguém chegou a dizer, um tanto quanto pitorescamente, que eu seria capaz de fazê-los chorar numa simples aula sobre os 
títulos de crédito... Não obstante o tom reprovador de sua observação, temo que esse meu crítico terá sido excessivamente generoso para comigo... Estou muito distante, por certo, de operar tamanho milagre, mormente em se tratando de um tema de natureza técnica.

Mas, se algo de verdade existir nessa dura reprimenda, quantos excessos não estarei cometendo, no dia de hoje, em que pessoas extremamente queridas e em número tão expressivo se reúnem por um gesto de amor: o simples fato de comemorar os trinta anos de minha atividade docente, por certo marcada por graves omissões das quais nem mesmo logrei identificar...

Será que terei o dom de transformar este recinto num verdadeiro "vale de lágrimas" como está escrito numa de minhas diárias orações?...

Já não sou mais assim, por certo, tão povoado de emoções... Posso até mesmo dizer que nada mais "acontece em meu coração quando ele cruza a Ipiranga e a Avenida São João"... Tudo o que tinha para acontecer já foi e ficou perdido nas brumas labirínticas do tempo...

Mais uma dúvida $\mathfrak{x}$ das tantas com as quais tenho convivido $\mathfrak{x}$ parece agora "roer as minhas unhas": serei eu o vil intérprete dos textos normativos e das lições dos mestres, recheando-os de impressões pessoais capazes de alterar-lhes o significado, passando aos destinatários de minhas preleções algo de errado ou, pelo menos, distorcido?...

Independentemente dessa resposta, é claro, já sei ter soado (e um tanto quanto serodiamente) a hora de parar a longa jornada... Prosseguirei mais algum tempo, é verdade, mas já não mais "leito um cego tcimoso" $x$ como sempre gostei de dizer, recordando-me de um verso de Fernando Pessoa, expresso pela pena de um de seus mais belos heterônimos, Alberto Caeiro æ, mas para completar as tarefas de orientação que se acham a meio caminho...

E, como gosto mesmo, a despeito de meus críticos, de misturar literatura com Direito, sempre que pertinente me parecer tal paralelismo, evoco, agora, um princípio de direito penal, segundo o qual a pena não deve nunca ultrapassar a própria pessoa do réu... Fico até um pouco constrangido em falar de direito penal æ disciplina normativa pela quạl sempre senti uma espécie de amor platônico $\mathfrak{x}$ na presença de alguns queridos amigos e amigas penalistas, tanto lá do Tribunal quanto de fora, que conhecem profundamente esse ramo do Direito.

Confesso já que por ser uma noile de amor é também de confissões -, igualmente, não captar tantos problemas nas aproximações entre a Poesia e o Direito. Numa dessas minhas manias, observei que o nosso grande Pontes de Miranda, no 
prólogo de um de seus livros que nada parece ter de conteúdo jurídico (Obras Literárias, Poesia/Prosa, Livraria José Olympio Editora, Rio de Janeiro, 1960, p. 7) -, com propriedade e encanto, diz: "Há esquisita delícia em pensar. Na agitação quotidiana da vida, quando nos sentimos em imediato contato com a realidade, ou deixamos que nos avassale a dor das impressões de há pouco, existe sempre um momento em que nos extasiamos e revivemos a vida. Sentir, reviver, pensar: é a mesma coisa. Pensaro que se sentiu é vivê-lo mais uma vez. A própria idéia deve ser a forma espiritual de pedaço de vida que se revive. Também a memória possui sabedoria: atravessamos a vida sem parar, vivendo sempre; mas, ao recordar o que se viveu, ressentimo-lo aos fragmentos, deliciando-nos, escolhendo."

Enfim, meus queridos Amigos e Amigas, é hora de encerrar. Não quero que a alma constelada de infinitas decepções lhes transmita, indevidamente, a tristeza e o enfado de seu próprio cansaço... A epígrafe de Valéry - "Les événements m'ennuyent" ou, em vernáculo, "os acontecimentos me aborrecem" -, constante de um de meus poemas, sempre foi minha eterna companheira e ela aparece agora mais verdadeira do que nunca, embora um momento doce e terno como este constitua uma exceção quase inacreditável que me acompanhará, certamente, para o resto de minha vida... Sobretudo quando penso que esta festa não fui eu quem a fez: foram todos vocês, menos eu, que a fizeram...

Quero, antes, dizer-lhes - mesmo com o receio íntimo de ser acusado, mais uma vez, de pecar pelos excessos literários - que a tragédia de minha vida ainda não se terá consumado de todo e ainda hei de escrevê-la... Espera-me o alto da montanha, onde irei passar meus derradeiros dias, assim que a justiça dos homens reconhecer (quem sabe?) que já trabalhei mais de quarenta anos e que já tenho o direito de me recolher no aconchego do claustro, para que bem longe das vanidades de nossa época falida, possa ter muito ainda o que escrever, o que contar e, sobretudo, o que esquecer e o que lembrar...

Espero, enfim, poder legar alguma coisa, ainda que seja a derradeira utopia de minha vida: a de que terei contribuído, de alguma forma, ainda que mínima, para que estas sete palavras: ódio, inveja, fome, miséria, intolerância, ingratidão e injustiça possam vir a ser estudadas pelos nossos netos, um dia, como sendo apenas simples arcaísmos...

A etimologia da palavra utopia tem tudo, efetivamente, a ver comigo: nunca estou, nem estive em nenhuma parte... E para que servem as utopias? Alguém já respondeu que elas servem para caminhar... 
Estou bem ciente de que, apesar de tantas utopias, ficam sempre mais coisas más do que boas... Não é à toa que, na epígrale de um de meus poemas, evoquei aquela arrepiante passagem de Shakespeare (na peça Júlio César, ato II, fala de Marco Antônio):

"O mal que os homens fazem vive depois deles. O bem que puderam fazer permanece quase sempre enterrado com os seus ossos."

Não sou homem de lazer grandes perorações, mas termino com o que deve ser terminado, isto é, com os meus mais sinceros agradecimentos, aquecidos com o vinho quente do coração que ora me sobe à cabeça, ainda que "espessa":

Ao Eminente Professor c Querido Amigo Cândido Rangel Dinamarco, pelas palavras excessivamente generosas e encantadoras com que me saudou; ào lado de tantas virludes que expressam, lambém não me deixam tão-só nos excessos que cometo...

Ao Eminente Ministro Ruy Rosado de Aguiar, do STJ, não-só pela sua presença neste encontro, que tanto me honra, mas pela forma carinhosa com que aceitou prefaciar o meu mais recente trabalho sobre a Teoria Geral da Relação Jurídica de Consumo;

À Acadcmia Paulista dos Magistrados, pela afetuosa homenagem que me foi prestada recentemente;

Aos membros da Comissão Organizadora desta noite: Adalberto Simão Filho, llene Patrícia de Noronha, Leslie Amendolara, Ligia Maria Simão, Marcus Elidius de Almeida e Regis Magalhães Soares de Qucirós, pelas tantas horas perdidas na preparação desta confraternização que se tornará um momento imperecível em minha vida...

Por derradeiro o comovido agradecimento à minha família, que tanto sofre com meu quase constante afastamento; ao pai saudoso, que se foi no mesmo dia de minha posse como magistrado no Tribunal c com quem, desde então, só converso por intermédio de minhas orações e da fé cristã; aos amigos todos que colecionci durante a vida, aos meus companheiros da Universidade de São Paulo, do Tribunal, da Justiçà Federal, da Academia dos Magistrados, do Instituto dos Advogados, das várias entidades que apoiaram a realização deste evento por certo imerecido alunos e alunas, exalunos c ex-alunas, quer de São Paulo, quer de outros Estados de nossa Federação, cuja presença tanto me emociona...

Vocês todos que estão aqui são os meus verdadeiros amigos... Não são 
como aqueles que proliferam em nossa época e que mais se assemelham às andorinhas, pois voltam no verão da prosperidade e partem no inverno das aflições, como já se disse algures...

Queridos Amigos e Amigas:

O meu destino, na noite de hoje, parece ter descrito uma curiosa parábola que começou, não propriamente há trinta anos, objeto desta comovida e próxima comemoração, mas há cxatos 38 anos, quando, cm nome de minha Turma do Curso Clássico do Colégio Rio Branco, fui escolhido para a saudação de despedida e termineia com um poema cheio de amor, de nosso Poeta Maior, Carlos Drummond de Andrade. Com aqueles mesmos versos - que outrora me provocaram na medula o mágico arrepio concluo minhas palavras:

"Amar solenemente as palmas do deserto,

o que é entrega ou adoração expectante, e amar o inóspito, o cru, una vaso sem flor, um chão de ferro, e o peito inerte, e a rua vista em sonho e uma ave de rapina.

Este o nosso destino: amor sem conta, distribuido pelas coisas pérficlas ou mulas, doação ilimitada a uma completa ingratidão. e na concha vazia do amor a procura medrosa, paciente, de mais e mais amor.

Amar a nossa falta mesma de amor; e na secura nossa amar a água implícita, e o beijo tácito, e a sede infinita."

Muito obrigado a todos, que Deus os abençoe sempre... 


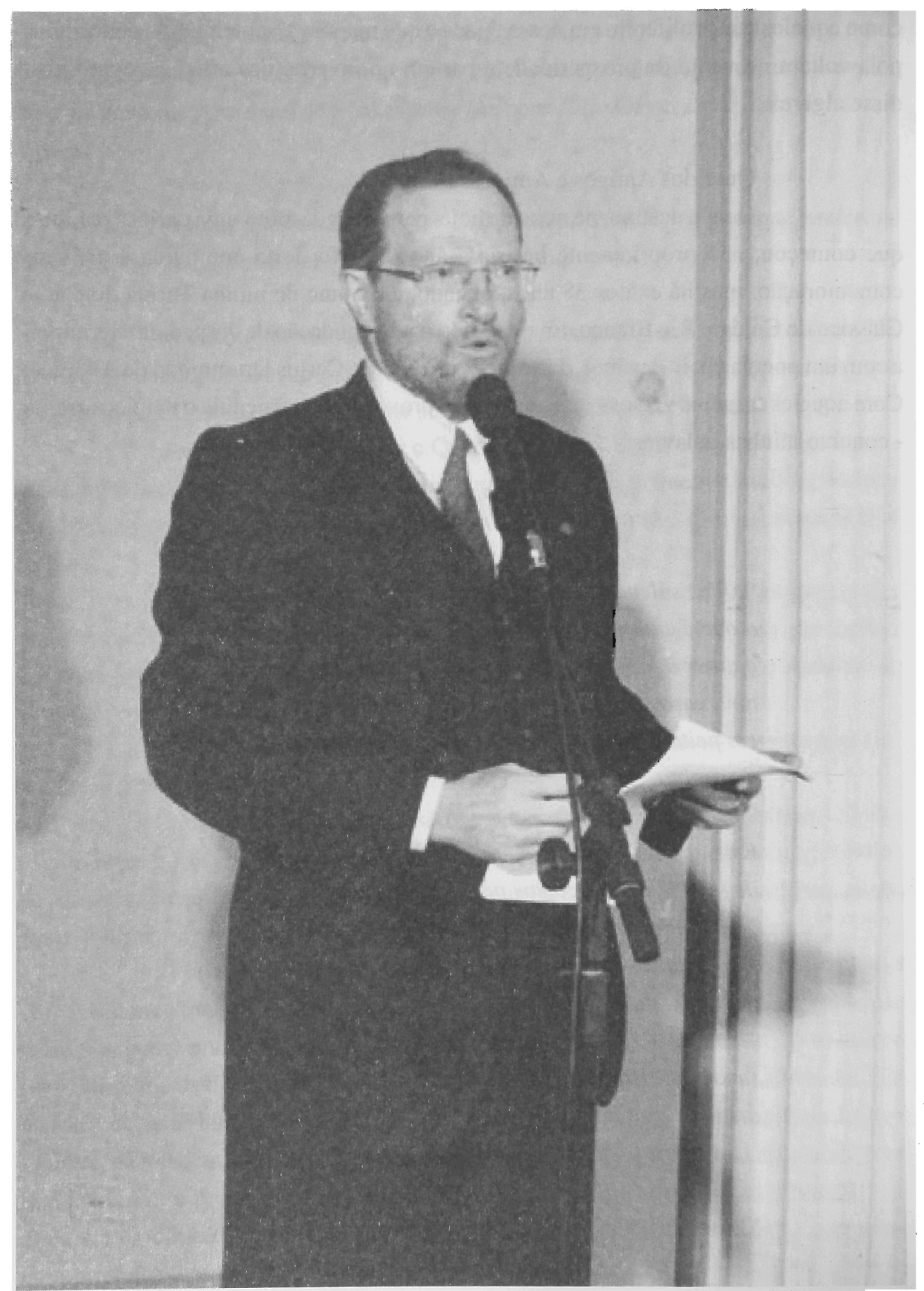

Professor Associado Newton De Lucca 